\title{
Kalp Damar Cerrahisi Yoğun Bakım Hemşirelerinde Şefkat Yorgunluğu ve Etkileyen Faktörlerin Belirlenmesi
}

\section{Compassion Fatigue in Cardiovascular Surgery Intensive Care Nurses and Determination Of Affecting Factors}

\author{
Yasemin Uslu ${ }^{1 *}$, Fatma Demir Korkmaz ${ }^{2}$ \\ ${ }^{1}$ Acıbadem Mehmet Ali Aydınlar Üniversitesi Sağlık Bilimleri Fakültesi, İstanbul, Türkiye \\ ${ }^{2}$ Ege Üniversitesi Hemşirelik Fakültesi Cerrahi Hastalıklar Hemşireliği Anabilim Dalı, İzmir, Türkiye \\ e-mail: yaseminuslu86@gmail.com,fatma.demir@ege.edu.tr \\ ORCID: 0000-0001-5727-3753 \\ ORCID: 0000-0003-3810-297X \\ *Sorumlu Yazar / Corresponding Author: Sorumlu Yazar: Yasemin Uslu ${ }^{1}$ \\ Gönderim Tarihi / Received: 26.12.2019 \\ Kabul Tarihi / Accepted: 03.04.2020 \\ DOI: $10.34087 /$ cbusbed.665597
}

Giriş ve Amaç: Şefkat yorgunluğu acı çeken bireylere harcanan yoğun bedensel ve duygusal güçten dolayı hastadan duygusal olarak uzaklaşmadır. Bu çalışma kalp damar cerrahisi yoğun bakım ünitesinde çalışan hemşirelerde şefkat yorgunluğunu ve etkileyen faktörleri belirlemek amaciyla yapıldı.

Gereç ve Yöntemler: Tanımlayıcı tipteki bu çalışmanın örneklemini İstanbul'da bulunan özel bir sağlık grubuna ait beş hastane ve İzmir'de bulunan bir üniversite hastanesinin kalp damar cerrahisi yoğun bakım ünitelerinde çalışmakta olan 76 hemşire oluşturdu. Veriler Nisan- Temmuz 2016 tarihleri arasında sosyodemografik veriler ve Çalışanlar için Yaşam Kalitesi Ölçeği ile toplandı. Çalışmanın sürdürülebilmesi için gerekli izinler alındı.

Bulgular: Hemşirelerin Şefkat Yorgunluğu alt boyutundan aldıkları puanlar 0 ile 38 arasında değişmekte olup,

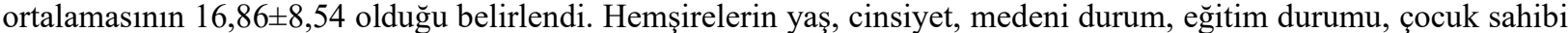
olma durumu, çalıșma süresi, bir şiftte ortalama bakım verilen hasta sayısı ve işini sevme durumlarına göre şefkat yorgunluğu puanları arasında istatistiksel olarak anlamlı bir farklılık bulunmadı $(\mathrm{p}>0,05)$. Düzensiz meslek içi eğitim alan hemşirelerin şefkat yorgunluğu alt boyutu puanları, düzenli meslek içi eğitim alan hemşirelerden istatistiksel olarak anlamlı düzeyde yüksek bulundu (p:0,025; $<<0,05)$

Sonuç: Calıșma kapsamında kalp damar cerrahisi yoğun bakım hemșirelerinin șefkat yorgunluğu düzeyleri orta olup düzenli hizmet içi eğitim almanın şefkat yorgunluğu gelişimini önlemede önemli olduğu belirlendi. Hemşirelerde şefkat yorgunluğu gelişimini önlemek için eğitim, danışmanlık ve destek programları yapılması önerilmektedir.

Anahtar kelimeler: Kalp Damar Cerrahisi Hemşireliği, şefkat, şefkat yorgunluğu

\footnotetext{
Abstract

Objective: Compassion fatigue is the emotional withdrawal from the patient due to the intense physical and emotional strength exerted on suffering individuals. This study aims to determine compassion fatigue and affecting factors in nurses working in the cardiovascular surgery intensive care unit.

Materials and Methods: The sample of this descriptive study consisted of 76 nurses working in the cardiovascular surgery intensive care units of five hospitals of a private health group in Istanbul and a university hospital in Izmir. The data were collected between April and July 2016 by using sociodemographic data and the Professional Quality of Life Scale.

Results: The score that nurses obtained from Compassion Fatigue sub-dimension ranged between 0 to 38 and the mean value was determined to be $16.86 \pm 8.54$. There was no statistically significant difference between compassion fatigue scores according to nurses' age, gender, marital status, education level, having children, working time, the average number of patients in a shift and loving the job $(p>0,05)$. The compassion fatigue sub-dimension scores of nurses who received irregular vocational training were found to be statistically significantly higher than nurses who received regular vocational training $(\mathrm{p}: 0,025 ; \mathrm{p}<0,05)$.
} 
Conclusion: In the study, compassion fatigue levels of cardiovascular surgery intensive care unit nurses were determined to be moderate and regular vocational training was found to be important in preventing the development of compassion fatigue. Training, counseling and support programs are recommended to prevent the development of compassion fatigue in nurses.

Key Words: Cardiovascular Surgery Nursing, compassion, compassion fatigue

\section{Giriș}

Şefkat, bir başkasının çektiği acı veya sıkıntının bir başkası tarafından derinden hissedilmesidir [1]. Şefkat, insanları sıkıntılı durumlarda bir arada tutan, değerli ve önemli bir duygudur. Şefkat, bakımın bireysel, uygun ve doğru verilmesini ve anlaşılır sonuçlar alınmasını sağladığından bakımın kalitesini arttırır. Şefkat, kaliteli bakım vermek için hemşireyi motive eder ve hastaları cesaretlendirir [2]. Şefkatli bir hemşire de acı veren işlemleri yapmak zorunda kalabilir ancak acı verse dahi şefkatle yapılan her işlem daha az acı verecektir [3].

Şefkat yorgunluğu ise acı çeken bir insana yardım etmekten veya yardım etmeyi istemekten kaynaklanan ve bu kişiye karşı derin empati ve hüzün duygularının gelişimiyle kendini gösterir [4]. Şefkat yorgunluğu anlamina gelen "Compassion fatigue" ifadesi ilk kez 1992 yılında, hemşire Joinson tarafindan acil serviste çalışan hemşireler için kullanılmıştır [5]. Hemşirelik mesleği şefkat yorgunluğunun en ağır yaşandığ mesleklerden biridir [6]. Şefkat yorgunluğu belirtileri çok çeşitli olmakla birlikte üzüntü, depresyon, uyku bozukluğu, olumsuz baş etme davranışları, madde bağımlılı̆̆ı (sigara, alkol), geçmişe ait kaygı verici görüntüleri düşünme, karar vermede hatalar ve düşük benlik saygısı görülebilmektedir [6-8]. Yoğun Bakım Üniteleri hemşireler için stresli bir iş ortamıdır [9]. Yoğun bakımda yüksek teknoloji ile çalışmak, sürekli hasta değişiminin olması, sorumluluk ve beklentinin fazla olması, tekrarlanan üzüntü, ağrı ve ölüme tanıklık etmek hemşirelerde mesleki stresi artırabilir [10]. Yoğun bakım ünitesinde yatan hastalar genellikle sağlık çalışanına bağımlı ve bakıma muhtaç; dolayısıyla savunmasız ve kolay örselenebilir konumdadır. Yoğun bakımda şefkate anlam katan hemşirelerdir. Acıları dindiren tedaviden çok, şefkatli bakımdır [2].

Türkiye'de; hemşire sayısında yetersizlik, olumsuz çalışma koşulları, yas tutmak için yeterli zamanlarının olmaması ve kültürel olarak duygularını etkin şekilde ifade edememeleri gibi nedenlerden dolay1 hemşirelerde şefkat yorgunluğu oranının yüksek olabileceği düşünülmektedir [3]. Literatürde, özellikle acı çekme yaşantısının daha fazla görüldüğü birimler olan yoğun bakım, onkoloji, psikiyatri, diyaliz klinikleri gibi alanlarda şefkat yorgunluğuna ilişkin çalışmalar mevcuttur [7, 11-15]. Ancak Kalp damar cerrahisi yoğun bakım ünitelerinde (KDC YBÜ) yapılmış çalışma oldukça sınırlıdır [9]. Bu çalışma Türkiye'de KDC YBÜ hemşireleri ile yapılan ilk çalışma olması nedeniyle literatüre katkı sağlayacağı düşünülmektedir. Bu çalışma KDC YBÜ'de çalışan hemşirelerin yaşadıkları şefkat yorgunluğu ve bunu etkileyen faktörleri belirlemek amacıyla yapılmıştır. 2 .

\section{Materyal ve Metot}

\subsection{Araştırmanın Evreni ve Örneklemi}

Tanımlayıcı tipteki bu çalışmanın evrenini İstanbul ilinde bulunan özel bir sağlık grubuna bağlı beş hastane ve İzmir ilinde bulunan bir üniversite hastanesinin KDC YBÜ çalışmakta olan 84 hemşire oluşturdu. Araştırmada örneklem seçimine gidilmeyip evrenin tamamına ulaşılmaya çalışıldı. Araştırmanın amacı açıklandıktan sonra çalışmaya katılmayı gönüllü olarak kabul eden 76 hemşire araştırmanın örneklemini oluşturdu. Veriler Nisan- Temmuz 2016 tarihleri arasında toplandı.

\subsection{Veri Toplama Yöntemi}

Araştırmanın uygulanabilmesi için etik kurul (2016$5 / 28$ ) ve ilgili hastanelerin yönetiminden yazılı, hemşirelerden ise sözlü izin alındı. Araştırmanın amacı hizmet içi eğitim sonrası uygun zamanda hemşirelere açıklandı ve veri toplama formları dağıtıldı. Verilerin değerlendirilmesini bireysel olarak uygun zamanda yapmaları istendi. Bir hafta sonra veri formları tekrar geri topland. Hemşirelerin 4'ü çalışmaya katılmak istemedi, 2'si yıllık izinde ve 2'si raporlu olması nedeniyle çalışma kapsamına alınmadı.

\subsection{Veri Toplama Araçları}

Verilerin Toplanmasında Birey Tanılama Formu ve Çalışanlar için Yaşam Kalitesi Ölçeği (ÇYKÖ) kullanılmıştır.

Çalışanlar için Yaşam Kalitesi Ölçeği: Stamm (2005) tarafindan hazırlanan ve mesleki tatmin, eşduyum/şefkat yorgunluğu ve tükenmişlik belirtilerini saptamak için geliştirilen ölçeğin Türkçe geçerlik güvenirliği Yeşil ve arkadaşları tarafından (2010) yapılmıştır. ÇYKÖ’nün güvenilirliğini değerlerinden cronbach alfa katsayısı 0.848 olarak bulunmuştur $[16,17]$.

Çalışanlar için Yaşam Kalitesi Ölçeğinin alt ölçeği; şefkat yorgunluğu, stres verici olayla karşılaşma sonucunda ortaya çıkan belirtileri ölçmek için oluşturulmuş bir testtir. Bu ölçekten yüksek puan alan çalışanlara bir destek veya yardım alması önerilmektedir. Ölçekteki 2, 5, 7, 9, 11, 13, 14, 23, 25, 28. maddeler bu durumu ölçmek için geliștirilmiş maddelerdir. Ölçekteki maddelerin değerlendirilmesi 
"Hiçbir zaman" (0) ile "Çok sık" (5) arasında değişen altı basamaklı bir çizelge üzerinden yapılmıştır. Ölçekten alınan puan ortalamaları düşük $(<8$ puan), orta $(9-16$ puan) ve yüksek (>17 puan) düzeyde şefkat yorgunluğu olarak yorumlanmaktadır [17]. Bu çalışmada Şefkat Yorgunluğu alt boyutunun Cronbach Alfa iç tutarlılık katsayısı 0,867 olarak bulundu.

\subsection{Verilerin Analizi}

Verilerin değerlendirilmesinde IBM SPSS Statistics 22 (IBM SPSS, Türkiye) programı kullanıldı. Verilerin normal dağılıma uygunluğu Shapiro-Wilks testi ile değerlendirildi. Tanımlayıcı istatistiksel metotların (Ortalama, Standart sapma, Frekans) yanı sira normal dağılım gösteren verilerin karşılaştırmalarında Student t testi, normal dağılım göstermeyen verilerin karşılaştırmalarında ise Mann-Whitney U testi kullanıldı. İç tutarlılığın değerlendirilmesinde Cronbach Alpha iç tutarlılık katsayısı kullanıldı. Anlamlılık $\mathrm{p}<0,05$ düzeyinde değerlendirildi.

\subsection{Araștırmanın Sinırlılıkları}

Çalışma sonuçları çalışmaya katılmayı kabul eden hemşireler ve çalışmanın yürütüldüğ̈̈ hastaneler için genellenebilir. Şefkat yorgunluğunu etkileyen demografik veriler sorgulanmasına rağmen burada etkili olabilecek kişilik özellikleri sorgulanmamıştır.

\section{Bulgular}

Hemșirelerin \%78,9'u (n=60) kadın, \%21,2'i (n=16) erkek olup yaş ortalaması 26,68 $\pm 5,64$ yaştır Hemşirelerin \%64,5'inin (n=49) özel hastanede çalıştığ 1 , \%75'inin $(\mathrm{n}=57)$ bekar, \%48,7'sinin $(\mathrm{n}=37)$ lisans mezunu ve \%17,1'inin $(n=13)$ çocuk sahibi olduğu saptand 1 (Tablo 1).

Tablo 1. Hemşirelerin Genel Özelliklerinin Dağılımı $(\mathrm{n}=76)$

\begin{tabular}{|c|c|c|c|}
\hline $\begin{array}{l}\text { Genel } \\
\text { Özellikler }\end{array}$ & & $\mathrm{n}$ & $\%$ \\
\hline \multirow[t]{2}{*}{ Cinsiyet } & Kadın & 60 & 78,9 \\
\hline & Erkek & 16 & 21,1 \\
\hline \multirow[t]{2}{*}{ Yaş grubu } & $\leq 25$ yaş & 39 & 51,3 \\
\hline & $>25$ yaş & 37 & 48,7 \\
\hline \multirow[t]{2}{*}{ Medeni durum } & Evli & 19 & 25,0 \\
\hline & Bekar & 57 & 75,0 \\
\hline \multirow[t]{4}{*}{$\begin{array}{l}\text { Eğitim } \\
\text { durumu }\end{array}$} & $\begin{array}{l}\text { Sağlık meslek } \\
\text { lisesi }\end{array}$ & 22 & 28,9 \\
\hline & Ön lisans & 12 & 15,8 \\
\hline & Lisans & 37 & 48,7 \\
\hline & Lisansüstü & 5 & 6,6 \\
\hline \multirow[t]{2}{*}{$\begin{array}{l}\text { Çalışılan } \\
\text { kurum }\end{array}$} & $\begin{array}{l}\text { Üniversite } \\
\text { Hastanesi }\end{array}$ & 27 & 35,5 \\
\hline & Özel Hastane & 49 & 64,5 \\
\hline \multirow{3}{*}{$\begin{array}{l}\text { Çocuk sahibi } \\
\text { olma }\end{array}$} & Evet & 13 & 17,1 \\
\hline & Hayır & 63 & 82,9 \\
\hline & & $\begin{array}{l}\text { Min- } \\
\text { Maks }\end{array}$ & Ort \pm SS \\
\hline $\begin{array}{l}\text { Çocuk sayısı } \\
(\mathrm{n}=13)\end{array}$ & & $1-3$ & $1,62 \pm 0,77$ \\
\hline
\end{tabular}

Tablo 2'de görüldüğü gibi, hemşirelerin meslekte

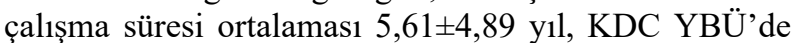
çalışma süreleri ortalaması $3,77 \pm 3,88$ yıldır. Hemşirelerin çalıştıkları KDC YBÜ yatak kapasitesi 5 ile 20 arasında değişmekte olup, ortalaması 12,33 $\pm 3,58$ yataktır. Hemşirelerin bir şiftte bakım verdikleri ortalama

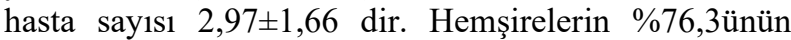
$(n=58)$ hemşire ve $\% 60,5$ 'inin $(n=46)$ haftada 50 saat ve üzerinde çalıştı̆̆ saptand1.

Hemşirelerin \%60,5'inin (n=46) sıklıkla gece çalıştığ 1 , $\% 39,5$ 'inin $(n=30)$ düzenli olarak hizmet içi eğitim alırken, \%60,5'inin (\%46) düzenli hizmet içi eğitim almadığı belirlendi. Hemşirelerin \%89,5'inin $(n=68)$ işini sevdiği, \%69,7'sinin $(\mathrm{n}=53)$ mesleğini kendi isteğiyle seçtiği belirlendi (Tablo 2).

Hemşirelerin Şefkat Yorgunluğu alt boyutundan aldığ puan ortalamasi 16,86 $\pm 8,54(\min 0$-max:38, medyan 15$)$ olup şefkat yorgunluğu düzeyleri orta olarak belirlendi.

Tablo 2. Hemşirelerin Çalıştıkları Kliniklere İlişkin Özelliklerinin Dağılımı (N=76)

\begin{tabular}{|c|c|c|c|}
\hline \multicolumn{2}{|c|}{ Kliniklere ilişkin özellikler } & $\begin{array}{l}\text { Min- } \\
\text { Maks }\end{array}$ & Ort \pm SS \\
\hline \multicolumn{2}{|c|}{$\begin{array}{l}\text { Hemşire olarak çalışma süresi } \\
\text { (y1l) }\end{array}$} & $1-23$ & $5,61 \pm 4,89$ \\
\hline \multicolumn{2}{|c|}{$\begin{array}{l}\text { KDC YBÜ'de çalışma süresi } \\
(\mathrm{y} 1 \mathrm{l})\end{array}$} & $0,5-23$ & $3,77 \pm 3,88$ \\
\hline \multicolumn{2}{|c|}{ KDC YBÜ yatak kapasitesi } & $5-20$ & $12,33 \pm 3,58$ \\
\hline \multicolumn{2}{|c|}{$\begin{array}{l}\text { Bir şiftte ortalama bakım } \\
\text { verilen hasta sayısı }\end{array}$} & $1-7$ & $2,97 \pm 1,66$ \\
\hline & & $\mathbf{n}$ & $\%$ \\
\hline \multirow{4}{*}{$\begin{array}{l}\text { KDC YBÜ } \\
\text { Hemşiresinin } \\
\text { görevi }\end{array}$} & Hemşire & 58 & 76,3 \\
\hline & Ekip lideri & 12 & 15,8 \\
\hline & $\begin{array}{l}\text { Eğitim } \\
\text { hemşiresi }\end{array}$ & 2 & 2,6 \\
\hline & $\begin{array}{l}\text { Sorumlu } \\
\text { hemşire }\end{array}$ & 4 & 5,3 \\
\hline \multirow{3}{*}{$\begin{array}{l}\text { Haftalık } \\
\text { çalışma saati }\end{array}$} & 40 saat & 8 & 10,5 \\
\hline & 41-49 saat & 22 & 28,9 \\
\hline & $\geq 50$ saat & 46 & 60,5 \\
\hline \multirow{2}{*}{$\begin{array}{l}\text { Siklıkla } \\
\text { çalışılan şift }\end{array}$} & Gece & 46 & 60,5 \\
\hline & Gündüz & 30 & 39,5 \\
\hline \multirow[t]{2}{*}{$\begin{array}{l}\text { Hizmet içi } \\
\text { eğitim alma }\end{array}$} & $\begin{array}{l}\text { Düzenli } \\
\text { olarak }\end{array}$ & 30 & 39,5 \\
\hline & Düzensiz & 46 & 60,5 \\
\hline \multirow[t]{2}{*}{ İşini sevme } & Evet & 68 & 89,5 \\
\hline & Hayır & 8 & 10,5 \\
\hline \multirow{2}{*}{$\begin{array}{l}\text { Mesleği kendi } \\
\text { isteğiyle seçme }\end{array}$} & Evet & 53 & 69,7 \\
\hline & Hayır & 23 & 30,3 \\
\hline
\end{tabular}

Hemşirelerin yaş grupları $(\mathrm{p}=0,272)$, cinsiyeti $(\mathrm{p}=0,358)$, medeni durumu $(p=0,352)$, eğitim durumu $(p=0,495)$, ve çocuk sahibi olma durumu $(p=0,185)$ ile şefkat yorgunluğu puanları arasında istatistiksel olarak anlamlı bir farklılık bulunmadi ( $>00,05$ ) (Tablo 3 ).

Hemşirelerin görevleri $(\mathrm{p}=0,603)$, hemşire olarak çalışma süresi $(\mathrm{p}=0,715), \mathrm{KDC}$ YBÜ’de çalışma süresi 
Tablo 3. Hemşirelerin Genel Özelliklerine Göre Şefkat Yorgunluğu Alt Boyut Puanlarının Değerlendirilmesi

\begin{tabular}{|c|c|c|c|}
\hline \multicolumn{2}{|l|}{ Genel Özellikler } & \multirow{2}{*}{$\begin{array}{l}\mathbf{n} \\
39\end{array}$} & \multirow{2}{*}{ 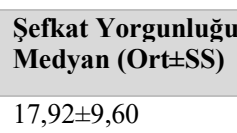 } \\
\hline Yaş grubu & $\leq 25$ yaş & & \\
\hline & $>25$ yaş & 37 & $15,76 \pm 7,22$ \\
\hline & $\mathbf{T}$ & & 1,107 \\
\hline & ${ }^{1} \mathbf{p}$ & & 0,272 \\
\hline \multirow[t]{4}{*}{ Cinsiyet } & Kadın & 60 & $16,40 \pm 8,39(15)$ \\
\hline & Erkek & 16 & $18,63 \pm 9,17(15,5)$ \\
\hline & $\mathbf{Z}$ & & $-0,919$ \\
\hline & ${ }^{2} \mathbf{p}$ & & 0,358 \\
\hline \multirow[t]{4}{*}{ Medeni durum } & Evli & 19 & $18,00 \pm 8,16(15)$ \\
\hline & Bekar & 57 & $16,49 \pm 8,7(15)$ \\
\hline & $\mathbf{Z}$ & & $-0,931$ \\
\hline & ${ }^{2} \mathbf{p}$ & & 0,352 \\
\hline \multirow[t]{4}{*}{ Eğitim durumu } & $\begin{array}{l}\text { Ön lisans } \\
\text { ve altı }\end{array}$ & 34 & $17,62 \pm 9,27$ \\
\hline & $\begin{array}{l}\text { Lisans ve } \\
\text { üzeri }\end{array}$ & 42 & $16,26 \pm 7,96$ \\
\hline & $\mathbf{T}$ & & 0,686 \\
\hline & ${ }^{1} \mathbf{p}$ & & 0,495 \\
\hline \multirow{4}{*}{$\begin{array}{l}\text { Çocuk sahibi } \\
\text { olma }\end{array}$} & Evet & 13 & $18,85 \pm 6,18(15)$ \\
\hline & Hayır & 63 & $16,46 \pm 8,94(15)$ \\
\hline & $\mathbf{Z}$ & & $-1,327$ \\
\hline & ${ }^{2} \mathbf{p}$ & & 0,185 \\
\hline
\end{tabular}

${ }^{1}$ Student t Testi, ${ }^{2}$ Mann Whitney U Test, Ort.: ortalama, SS: standart sapma

$(\mathrm{p}=0,821)$, ortalama bakım verilen hasta sayıs $(p=0,231)$, sıklıkla çalışılan şift $(p=0,805)$, işinini sevme durumu $(p=0,865)$ ve mesleği kendi isteğiyle seçme durumları $(p=0,777)$ ile şefkat yorgunluğu puanları arasında istatistiksel olarak anlamlı bir farklılık bulunmadi $(\mathrm{p}>0,05)$ (Tablo 4).
Tablo 4. Hemşirelerin Çalışma koşulları ile Şefkat Yorgunluğu Alt Boyut Puanları arasındaki ilişkinin Değerlendirilmesi

\begin{tabular}{|c|c|c|c|}
\hline \multicolumn{2}{|l|}{$\begin{array}{l}\text { Çalışılan Kliniklere } \\
\text { İlişkin Özellikler }\end{array}$} & \multirow{2}{*}{$\begin{array}{l}\mathbf{n} \\
58\end{array}$} & \multirow{2}{*}{$\begin{array}{l}\text { Şefkat } \\
\text { Yorgunluğu } \\
\text { Ort } \pm \text { SS } \\
\text { (Medyan) } \\
16,47 \pm 7,83(15)\end{array}$} \\
\hline \multirow{4}{*}{$\begin{array}{l}\text { KDC YBÜ } \\
\text { hemşiresinin görevi }\end{array}$} & Hemşire & & \\
\hline & $\begin{array}{l}\text { Ekip lideri } \\
\text { ve diğer }\end{array}$ & 18 & $\begin{array}{l}18,17 \pm 10,67 \\
(15)\end{array}$ \\
\hline & $\mathbf{Z}$ & & $-0,520$ \\
\hline & $1 p$ & & 0,603 \\
\hline \multirow{4}{*}{$\begin{array}{l}\text { Hemşire olarak çalışma } \\
\text { süresi }\end{array}$} & 1-5 yıl & 51 & $16,61 \pm 8,86(15)$ \\
\hline & $\geq 6$ yll & 25 & $17,40 \pm 8,01(15)$ \\
\hline & $\mathbf{Z}$ & & $-0,366$ \\
\hline & ${ }^{1} \mathbf{p}$ & & 0,715 \\
\hline \multirow{4}{*}{$\begin{array}{l}\text { KDC YBÜ'de çalışma } \\
\text { süresi }\end{array}$} & $\leq 2$ yll & 34 & $17,12 \pm 7,58$ \\
\hline & $>2$ yll & 42 & $16,67 \pm 9,34$ \\
\hline & $\mathbf{T}$ & & 0,227 \\
\hline & ${ }^{2} \mathbf{p}$ & & 0,821 \\
\hline \multirow[t]{4}{*}{ Haftalık çalışma saati } & $<50$ saat & 30 & $14,70 \pm 7,14$ \\
\hline & $\geq 50$ saat & 46 & $18,28 \pm 9,14$ \\
\hline & $\mathbf{T}$ & & $-1,814$ \\
\hline & ${ }^{1} \mathbf{p}$ & & 0,074 \\
\hline \multirow{4}{*}{$\begin{array}{l}\text { KDC YBÜ yatak } \\
\text { kapasitesi }\end{array}$} & $<15$ adet & 49 & $17,61 \pm 9,31(16)$ \\
\hline & $\geq 15$ adet & 27 & $15,52 \pm 6,90(15)$ \\
\hline & $\overline{\mathbf{Z}}$ & & $-1,163$ \\
\hline & ${ }^{1} \mathbf{p}$ & & 0,245 \\
\hline \multirow{4}{*}{$\begin{array}{l}\text { Bir şiftte ortalama } \\
\text { bakım verilen hasta } \\
\text { sayısı }\end{array}$} & $<3$ hasta & 40 & $15,75 \pm 8,90$ \\
\hline & $\geq 3$ hasta & 36 & $18,11 \pm 8,07$ \\
\hline & $\mathbf{T}$ & & $-1,207$ \\
\hline & ${ }^{2} \mathbf{p}$ & & 0,231 \\
\hline \multirow[t]{4}{*}{ Sıklıkla çalışılan şift } & Gece & 46 & $17,07 \pm 8,19$ \\
\hline & Gündüz & 30 & $16,57 \pm 9,19$ \\
\hline & $\mathbf{T}$ & & 0,247 \\
\hline & ${ }^{2} \mathbf{p}$ & & 0,805 \\
\hline \multirow[t]{4}{*}{ Meslek içi eğitim alma } & $\begin{array}{l}\text { Düzenli } \\
\text { olarak }\end{array}$ & 30 & $14,17 \pm 8,21$ \\
\hline & Düzensiz & 46 & $18,63 \pm 8,37$ \\
\hline & $\mathbf{T}$ & & $-2,289$ \\
\hline & ${ }^{2} \mathbf{p}$ & & $0,025 *$ \\
\hline \multirow[t]{4}{*}{ İşini sevme durumu } & Evet & 68 & $16,96 \pm 8,60(15)$ \\
\hline & Hayır & 8 & $\begin{array}{l}16,13 \pm 8,51 \\
(15,5)\end{array}$ \\
\hline & $\mathbf{Z}$ & & $-0,170$ \\
\hline & ${ }^{1} \mathbf{p}$ & & 0,865 \\
\hline \multirow{4}{*}{$\begin{array}{l}\text { Mesleği kendi isteğiyle } \\
\text { seçme durumu }\end{array}$} & Evet & 53 & $17,30 \pm 8,81(15)$ \\
\hline & Hayır & 23 & $15,87 \pm 7,98(16)$ \\
\hline & $\mathbf{Z}$ & & $-0,283$ \\
\hline & ${ }^{1} \mathbf{p}$ & & 0,777 \\
\hline
\end{tabular}

${ }^{1}$ Mann Whitney U Test, ${ }^{2}$ Student $\mathrm{t}$ Testi, ${ }^{*} \mathrm{p}<0,05,{ }^{* *} \mathrm{p}<0,01$

Düzensiz olarak meslek içi eğitim alan hemşirelerin şefkat yorgunluğu alt boyutu puanları, düzenli olarak meslek içi eğitim alan hemşirelerden istatistiksel olarak anlamlı düzeyde yüksek bulundu ( $\mathrm{p}: 0,025 ; \mathrm{p}<0,05)$ (Tablo 4)

\section{Tartışma}

Mesleki yaşam kalitesi, iş yaşamının olumlu ve olumsuz yönlerinden etkilenmektedir. İş yaşamının olumlu yönü mesleki memnuniyeti gösterirken, olumsuz yönü ise şefkat yorgunluğu olarak belirtilmektedir [18].

Cerrahi birimlerde çalışan hemşirelerin sık ve uzun süreli strese maruziyetleri nedeniyle şefkat yorgunluğu gelişimi 
açısından riskli oldukları belirtilmektedir [19]. Cerrahi hemşirelerinde, travma hastası ile çalışma dişında kurumsal ve politik nedenlerin de strese neden olduğu, sinirli ve gergin davranış biçimlerinin ortaya çıktığ 1 ifade edilmektedir (Schwam1998). Hooper ve arkadaşları (2010) çalışmasında acil hemşirelerinin \%86'sında orta ve yüksek düzeyde şefkat yorgunluğu saptanmıştır [7]. Travma hemşireleri ile yapılan bir çalışmada, hemşirelerin \%27,3'ünde şefkat yorgunluğu olduğu belirlenmiştir [11]. Transplantasyon hemşireleri ile yapılan çalışmada, şefkat yorgunluk düzeyleri orta düzeyde [20], hospiste çalışanlarda benzer şekilde orta düzeyde tespit edilmiştir $[12,13]$. Bu çalışmada da literatüre benzer olarak hemşirelerin şefkat yorgunluğunun orta düzeyde olduğu (mean;16,86 $\pm 8,54$ ) saptandı. Şefkat yorgunluğunun dağılımına bakıldığında hemşirelerin \%14'ünde ise yüksek düzey (18 puan ve üzeri) şefkat yorgunluğunun saptandı. KDC YBÜ’de çalışan hemşirelerin travmatik hasta ile s1k karşılaşmadıkları için şefkat yorgunluğu görülme oranlarının düşük olabileceği belirtilmektedir. KDC YBÜ hemşireleri ile yapılan bir çalışmada hemşirelerin \%44'ünde orta, \%56'sında düşük düzeyde şefkat yorgunluğu olduğu belirtilmiştir [9]. KDC YBÜ hemşirelerinin yüksek olmaması sevindirici olmakla beraber bu durum hasta sirkülasyonunun hızlı olması, hemşirelerin aynı hastayla çok uzun süre bir arada olmaması ile açıklanabilir. Hemşirelerin mesai saatleri içerisinde birbirlerini desteklemeleri ve çalışma saatleri dışında sosyal aktivitelere katılımları bu durumu desteklemiş olabilir.

$\mathrm{Bu}$ çalışmada, yaş, cinsiyet, medeni durum, eğitim durumu ve çocuk sahibi olma durumunun şefkat yorgunluğunu etkilemediği saptandı. Yapılan bir meta analizde de demografik özelliklerden yaş ve cinsiyetin şefkat yorgunluğu gelişiminde etkili olmadığ belirtilmektedir [21]. Acil, yoğun bakım, nefroloji ve onkoloji kliniklerinde çalışan hemşirelerde sosyodemografik değişkenlerle şefkat yorgunluğu arasında bir ilişki olmadığı [7] ancak kadınların erkek hemşirelerden daha fazla şefkat yorgunluğu yaşadığ belirlenmiştir [7, 22]. Sacco ve arkadaşları (2015) yaptığ 1 çalışmada ise hemşirelerin yaş, cinsiyet, eğitim düzeyi ve çalıştığ 1 birimin şefkat yorgunluğunu etkileyen temel değişkenler olduğu belirtilmektedir [14]. Çalışmada katılımcıların çoğunluğunun kadın cinsiyette olması nedeniyle bu sonuca ulaşılmış olabilir. Cinsiyet dağılımları eşit olan çalışma gruplarında daha güvenilir sonuçlara ulaşılacağı düşünülmektedir.

Eğitim seviyesinin artması ile bilginin koruyucu bir güç olduğu ve şefkat yorgunluğunun daha az görüldüğü belirtilmektedir [22]. Bu çalışma kapsamında, düzensiz olarak meslek içi eğitim alan hemşirelerin şefkat yorgunluğu alt boyutu puanlarının, düzenli olarak meslek içi eğitim alan hemşirelerden istatistiksel olarak anlamlı düzeyde yüksek olduğu saptanmıştır. Burada hizmetçi eğitim planlamaları ile hemşirelerin yetkinliklerinin ve bilimsel gücünün arıttırılmasının şefkat yorgunluğunun önlenmesinde önemli bir faktör olabileceği söylenebilir. Ayrıca eğitim seviyesinin artması ile kişilerin yönetimsel pozisyonda çalışmaları ve hastalarla teması azalttığından şefkat yorgunluğunun düşük görülebildiği vurgulanmaktadır [21]. Hemşirelerin eğitim seviyesinin düşük olmasının mesleki memnuniyetsizlik ve beraberinde şefkat yorgunluğu gelişimi açısından riski artırdığı [23, 24] [24], hemşirelerin şefkat yorgunluğu düzeyi ile eğitim düzeyi arasında ilişkinin anlamlı olduğu belirtilmektedir [20].

Şefkat yorgunluğu gelişiminde meslekte çalışma yılı önemli bir risk faktörüdür. Hemşirenin yaşı arttıkça

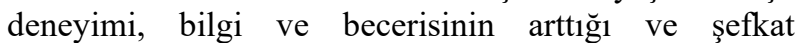
yorgunluğunun azaldığ 1 , genç ve/veya tecrübesi az olan hemşirelerin şefkat yorgunluğu gelişimi açısından riskli olduğu belirtilmektedir [25, 26]. Ancak Yu ve arkadaşları (2016) yaptı̆̆ı çalışmada onkoloji hemşirelerinde çalışma süresi fazla olanlarda şefkat yorgunluğu düzeyinin arttığı belirtilmektedir [15]. Ayrıca yoğun bakım hemşireleri ile yapılan bir çalışmada 50 yaş üzeri ve lisansüstü eğitime sahip hemşirelerde şefkat yorgunluğu düzeylerinin daha yüksek olduğu da bildirilmiştir [14]. Bu çalışmada mesleki çalışma yılı ile şefkat yorgunluğu gelişimi arasında anlamlı bir ilişki saptanmamıştır. Bu durumun çalışma grubundaki hemşirelerin yaş ortalamasının genç ve birbirine yakın olmasından kaynaklandığı düşünülmektedir.

Mesleki tatmin ve mesleği severek yapma şefkat yorgunluğu gelişiminde önemli koruyucu bir faktördür. Mesleğini severek yapmayan hemşirelerde şefkat yorgunluğu gelişme riskinin yüksek olduğu belirtilmektedir [17]. Kelly ve arkadaşlarının (2015) acil hemşireleri ile yaptıkları çalışmada mesleği severek yapma ve mesleki memnuniyetin şefkat yorgunluğunu etkilediği belirtilmektedir [11]. Yoğun bakım hemşireleri ile yapılan çalışmada mesleğini isteyerek seçenlerin mesleki memnuniyetlerinin yüksek olduğu belirtilmektedir [27]. $\mathrm{Bu}$ çalışmada hemşirelerin \%89,5'inin işini sevdiği, \%69,7'sinin mesleğini kendi isteğiyle seçtiği belirlenmiştir. Buna karşın bu çalışmada hemşirelik mesleğini severek yapma ve kendi isteğiyle seçmenin şefkat yorgunluğu gelişimi açısından ilişsili bir faktör olmadığı saptanmıştır. Bu durum hemşirelerde şefkat yorgunluğunun yüksek düzeyde çıkmadığından belirleyici bir faktör olmadığı düşünülmektedir.

\section{Sonuç}

$\mathrm{Bu}$ çalışmada KDC YB hemşirelerinin şefkat yorgunluğunun orta düzeyde olduğu saptanmıştır. Araştırmaya katılan hemşirelerin genç olduğu göz önüne alınırsa mesleki çalışma yılları ve yaşları arttıkça hemşirelerde şefkat yorgunluğu riskinin artabileceği şeklinde yorumlanabilir. Hemşirelerin şefkat yorgunluğu belirtileri ve müdahale stratejileri hakkında bilgi sahibi olmaları ve sağlıklı bir iş-yaşam dengesi sağlamaları için hem kurumsal hem de kişisel bir bakım planı geliştirmeleri önemlidir. Literatürde de sağlık hizmetleri sistemlerinin, şefkat yorgunluğunu önleyen ve şefkat yorgunluğu yaşayan hemşirelerin ihtiyaçlarını karşılayan sağlıklı çalışma ortamları yaratmasının önemli olduğu belirtilmektedir [6]. Şefkat yorgunluğunu önlemeye yönelik yönetimsel ve bireysel girişimlerin 
planlanmasının bakımın kalitesini artıracağı düşünülmektedir.

\section{Referanslar:}

1. Cornwell, J, Goodrich, J, Ensuing Compassionate Care in Hospital. Nursing Times Ethical, 2009, 7-9.

2. Uslu, Y, Demir Korkmaz, F, Yoğun Bakımda Hemşirenin Hissi Tarafı "Şefkat" ve Bakım. Yoğun Bakım Hemşireliği Dergisi, 2016. 20(2), 108-115.

3. Uslu, Y, Demir Korkmaz, F, Hemşirenin Hissi Tarafı Şefkatin Bedeli: Şefkat Yorgunluğu, Ege Üniversitesi Hemşirelik Fakültesi Dergisi, 2017, 33(1), 123-133.

4. Figley, CR, Compassion fatigue: Coping with secondary traumatic stress in those who treat the traumatized. 1995: Brunner/Mazel, Publishers.

5. Coetzee, SK, Klopper, HC, Compassion fatigue within nursing practice: A concept analysis, Nursing \& health sciences, 2010,12(2), 235-243.

6. Schroeter, K, Compassion fatigue: An unwanted reflection of your reality, 2014, LWW.

7. Hooper, C, et al., Compassion satisfaction, burnout, and compassion fatigue among emergency nurses compared with nurses in other selected inpatient specialties, Journal of Emergency Nursing, 2010, 36(5), 420-427.

8. Wakefield, E, Compassion fatigue in the perioperative environment. Journal of Perioperative Nursing, 2018, 31(2), 21.

9. Young, JL, et al., Compassion satisfaction, burnout, and secondary traumatic stress in heart and vascular nurses, Critical care nursing quarterly, 2011, 34(3),227-234

10. Van Mol, M, et al., The prevalence of compassion fatigue and burnout among healthcare professionals in intensive care units: a systematic review, PloS one, 2015, 10(8), e0136955.

11. Kelly, L, Runge, J, Spencer, C, Predictors of compassion fatigue and compassion satisfaction in acute care nurses. Journal of Nursing Scholarship, 2015, 47(6), 522-528.

12. Alkema, K., Linton, JM, Davies, R, A Study of the Relationship Between Self-Care, Compassion Satisfaction, Compassion Fatigue, and Burnout Among Hospice Professionals, Journal of Social Work in End-of-Life \& Palliative Care, 2008,4(2), 101-119.

13. Abendroth, M. and J. Flannery, Predicting the risk of compassion fatigue: A study of hospice nurses, Journal of Hospice and Palliative Nursing, 2006, 8(6), 346-356.

14. Sacco, T.L., et al., Compassion satisfaction and compassion fatigue among critical care nurses, Critical Care Nurse, 2015, 35(4), 32-42.

15. Yu, H, Jiang A, Shen J, Prevalence and predictors of compassion fatigue, burnout and compassion satisfaction among oncology nurses: A cross-sectional survey, International Journal of Nursing Studies, 2016, 57, 28-38.

16. Stamm, B, The concise manual for the professional quality of life scale. ProQOL.org ,Pocatello, ID 2010.

17. Yeşil, A., et al., Çalışanlar İçin Yaşam Kalitesi Ölçeği Türkçe Uyarlaması Geçerlik ve Güvenilirlik Çalışması, Archives Of Neuropsychiatry/Noropsikiatri Arsivi, 2010, 47(2).

18. Hall, D.S., Work-related stress of registered nurses in a hospital setting. Journal for Nurses in Staff Development, 2004, 20(1), 6-14.

19. Yoder, EA., Compassion fatigue in nurses. Applied nursing research, 2010, 23(4), 191-197.

20. Kim, SY, Compassion fatigue in liver and kidney transplant nurse coordinators: A descriptive research study, Progress in Transplantation, 2013, 23(4), 329-335

21. Zhang, YY, et al., Extent of compassion satisfaction, compassion fatigue and burnout in nursing: A meta-analysis, Journal of Nursing Management, 2018, 26(7), 810-819.

22. Mangoulia, P, et al., Prevalence of secondary traumatic stress among psychiatric nurses in Greece. Archives of Psychiatric Nursing, 2015, 29(5), 333-338.

23. Hegney, DG, et al., Compassion satisfaction, compassion fatigue, anxiety, depression and stress in registered nurses in A ustralia: study 1 results, Journal of NursingMmanagement, 2014, 22(4), 506-518.

24. Denk, T, Köçkar Ç, Compassion fatigue in nurses working in surgical clinics, Yaşam Becerileri Psikoloji Dergisi, 2018, 2(4), 237-245.

25. Paige LB, and Jaynelle SF, Nursing work environment and nurse caring: relationship among motivational factors, Journal of Advanced Nursing, 2010(8), 1819.
Kolthoff, KL, Hickman SE, Compassion fatigue among nurses working with older adults, Geriatric Nursing, 2017,38(2), 106-109.

27. Bitek, D, Akyol, A, Yoğun bakım hemșirelerinin çalıșma ortamına ilişkin algıları ile iş doyumları arasındaki ilişkinin incelenmesi, Yoğun Bakum Hemşireliği Dergisi, 2017,21(1), 1-6.

http://edergi.cbu.edu.tr/ojs/index.php/cbusbed isimli yazarın CBU-SBED başlıklı eseri bu Creative Commons Alınt1-Gayriticari4.0 Uluslararası Lisansı ile lisanslanmıştır.

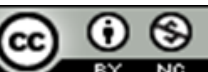

